Atıf için / For Citation: M. Sandal, Z. Yıldız, "Yüksek Boyutlu Veriler İçin BehrensFisher Probleminin Çözümü ve Önerilen Test İstatistiklerinin Karşılaştırılması", Süleyman Demirel Üniversitesi Fen Edebiyat Fakültesi Fen Dergisi, 16(2), 397-415, 2021.

\title{
Yüksek Boyutlu Veriler İçin Behrens-Fisher Probleminin Çözümü ve Önerilen Test İstatistiklerinin Karşılaştırılması
}

\author{
Mehmet SANDAL ${ }^{* 1}$, Zeki YILDIZ ${ }^{2}$ \\ ${ }^{1}$ Manisa Celal Bayar Üniversitesi, İktisadi ve İdari Bilimler Fakültesi, Ekonometri Bölümü, 45000, \\ Eskişehir, Türkiye \\ ${ }^{2}$ Eskişehir Osmangazi Üniversitesi, Fen-Edebiyat Fakültesi, İstatistik Bölümü, 26000, Eskişehir, Türkiye \\ *yazışlan yazar e-posta: mehmet.sandal@cbu.edu.tr \\ (Alınış: 05.03.2021, Kabul: 17.07.2021, Yayımlanma: 25.11.2021)
}

Özet: Çok değişkenli ikiden fazla grup ortalama vektörünün karşılaştırılması genellikle Çok Değişkenli Varyans Analizi (MANOVA) problemi olarak bilinmektedir. Ancak MANOVA problemlerinin çözümü için kullanılan klasik test istatistikleri, varsayım ihlallerinden oldukça fazla etkilenmektedir. Ayrıca bağımlı değişken sayısının gözlem sayısından daha büyük olduğu durumlarda çok değişkenli test istatistikleri yetersiz kalmaktadır. Bu çalışmanın amacı, yüksek boyutlu Behrens-Fisher problemlerinde ortalama vektörlerin eşit olup olmadığını belirlemek için önerilen bazı test istatistiklerini karşılaştırmaktır. $\mathrm{Bu}$ amaçla varyans-kovaryans matrislerinin heterojen olduğu durumlarda dört farklı test istatistiği için bir simülasyon analizi gerçekleştirilmiştir. Çalışmada üç farklı varyans-kovaryans modeli kullanılmıştır. Ayrıca bağımlı değişken sayısı ve gözlem sayısı için farklı deneysel koşullar dikkate alınmıştır. Çalışmanın sonuçları, test istatistiklerinin performanslarının genel olarak karşılaştırılabilir olduğunu göstermiştir. Ancak deneysel koşullara göre test istatistiklerinin performansının değiştiği gözlemlenmiştir.

Anahtar kelimeler: Çok değişkenli varyans analizi (MANOVA), Yüksek boyutlu veri, BehrensFisher problemi, Monte Carlo simülasyonu

\section{Solution of Behrens-Fisher Problem For High-Dimensional Data and Comparison of Proposed Test Statistics}

\begin{abstract}
Comparison of multivariate mean of more than two groups is generally known as multivariate variance analysis (MANOVA) problem. However, classical test statistics used to solve MANOVA problems are highly affected by assumption violations. In addition, multivariate test statistics are insufficient in cases where the number of dependent variables is greater than the number of observations. This study aims to compare some proposed test statistics to determine whether mean vectors are equal in high-dimensional Behrens-Fisher problems. For this purpose, a simulation analysis was carried out for four different test statistics in cases where variance-covariance matrices are heterogeneous. Three different variancecovariance models were used in the study. In addition, different experimental conditions were taken into account for the number of dependent variables and the number of observations. The results of the study showed that the performances of the test statistics were generally comparable. However, it has been observed that the performance of test statistics varies according to experimental conditions.
\end{abstract}

Key words: Multivariate variance analysis (MANOVA), High dimensional data, Behrens-Fisher problem, Monte Carlo simulation 


\section{Giriş}

İstatistiksel araştırmalarda ilgilenilen temel konulardan bir tanesi ortalama karşılaştırma problemidir. İki ya da daha fazla grup ortalamasının eşit olup olmadığını belirlemek için çeşitli istatistiksel tekniklere başvurulmaktadır. Ancak araştırma probleminin çözümünde bağımlı ve bağımsız değişken sayısına göre farklı istatistiksel yöntemlerin kullanılması gerekmektedir. Tek bir bağımlı değişken mevcut iken ikiden fazla grup ortalamasını karşılaştırmak için "Varyans Analizi (ANOVA)" yöntemi kullanılmaktadır. Ancak bağımlı değişken sayısı birden fazla olduğunda, değişkenler arasındaki ilişkilerinde dikkate alınması gerekmektedir. Üstelik doğru olan yokluk hipotezinin reddedilmesi durumunda I. tip hata yapılmaktadır. Her bir değişken için ayrı ayrı ANOVA uygulanması, değişkenler arasındaki ilişkilerin göz ardı edilmesine ve I. tip hata yapma olasılığının artmasına neden olmaktadır. Bu durumda testin güven düzeyi azalmaktadır. Dolayısıyla birden fazla bağımlı değişken için çok değişkenli istatistiksel tekniklerin kullanılmas1 gerekmektedir [1-2].

Çok değişkenli normal dağılıma sahip ikiden fazla grup ortalama vektörünün eşitlik sınaması genellikle "Çok Değişkenli Varyans Analizi (MANOVA)" problemi olarak tanımlanmaktadır. MANOVA'da, iki veya daha fazla bağımlı değişkenin aynı modelde değerlendirilmesi amaçlamaktadır. Böylece değişkenler arasındaki ilişkiler göz ardı edilmemektedir. MANOVA problemlerinin çözümü için genellikle [3-6] tarafından önerilen test istatistikleri kullanılmaktadır. $\mathrm{Bu}$ test istatistikleri, gruplar arasındaki anlamlı farklılıkları belirlemek için son derece önemlidir. Ancak test istatistiklerinin uygulanabilmesi için çok değişkenli normal dağılım ve varyans-kovaryans matrislerinin homojenlik varsayımlarının sağlanması gerekmektedir. Bu koşullar sağlandığı zaman son derece güçlü ve anlamlı sonuçlar elde edilebilmektedir. Varyans-kovaryans matrislerinin homojen olmadığ karşılaşılmaktadır. $\mathrm{Bu}$ problemin çözümünde [3-6] tarafından sunulan test istatistiklerinin kullanılması, bu istatistiklerin daha kötü bir performans ortaya koymasına neden olmaktadır.

MANOVA test istatistiklerinin hesaplanmasında bir başka problem ise varyanskovaryans matrislerinin tersine ihtiyaç duyulmasıdır. Varyans-kovaryans matrislerinin tersinin alınabilmesi için bağımlı değişken sayısının gözlem sayısından daha küçük olması gerekmektedir. Ancak bağımlı değişken sayısının gözlem sayısından daha büyük olduğu yüksek boyutlu veriler söz konusu olduğunda varyans-kovaryans matrisi tekil olmakta ve tersi alınamamaktadır [7]. Dolayısıyla yüksek boyutlu veriler söz konusu olduğunda da bilinen test istatistiklerinin özellikleri ve kullanılabilirlikleri kisitlanmaktadir.

Genetik bilimi başta olmak üzere tıp, biyoloji, endüstri, mühendislik vb. gibi birçok alanda yüksek boyutlu veriler ile sıklıkla karşılaşılmaktadır. Özellikle DNA mikrodizini üzerine yapılan araştırmalarda, daha küçük gözlemlerden elde edilen veriler için yüksek sayıdaki değişkene bağlı analizler gerçekleştirilmektedir. Son yıllarda hızlı bir gelişme gösteren teknoloji dünyası da yüksek boyutlu verilere ulaşılmasına ve bunların çözümlenmesine imkân sağlamaktadır. Bu durum yüksek boyutlu verilerin istatistiksel çalışmalardaki önemini de giderek artırmaktadır. Ancak boyut sayısının gözlem sayısından daha fazla olması, çeşitli hesaplama ve istatistiksel çözümleme zorlukları ortaya çıkarmaktadır [8]. Bu nedenle yüksek boyutlu verilerin analiz edilmesi için uygun istatistiksel tekniklerin geliştirilmesine ihtiyaç duyulmaktadır.

Yüksek boyutlu iki örneklem ve $k$ örneklem problemleri için varsayımların sağlandığ1 veya sağlanmadığı durumlara göre farklı çözümleme yaklaşımları benimsenmiştir. İki örneklem problemleri için ilk çalışmalar [9-12] tarafından gerçekleştirilmiştir. Yüksek 
boyutlu MANOVA problemlerinde normallik ve homojenlik varsayımlarının farklı durumları için [13-19] tarafindan çeşitli çözümleme yaklaşımları geliştirilmiştir. Ancak homojenlik varsayımının ihlal edildiği durumlarda yüksek boyutlu problemler için sınırlı sayıda test istatistiği önerilmiştir.

$\mathrm{Bu}$ çalışmanın amacı da yüksek boyutlu Behrens-Fisher problemlerinde ikiden fazla $(k>2)$ gruba ait ortalama vektörlerin eşitliğini sınamak için önerilen test istatistiklerini I. tip hata yapma olasılıkları ve güç değerleri bakımından karşılaştırmaktır. Bu amaçla çalışmanın üçüncü bölümünde, yüksek boyutlu veriler için önerilen test istatistikleri açıklanmıştır. Dördüncü bölümde, önerilen test istatistiklerinin farklı deneysel koşullar altında performanslarını belirlemek için bir simülasyon çalışması gerçekleştirilmiştir. Beşinci bölümde ise yüksek boyutlu $k$ örneklem Behrens-Fisher problemlerinin çözümü için önerilen test istatistikleri gerçek bir veri örneği üzerinde uygulanmıştır.

\section{Materyal ve Metot}

$\mu_{i}$ ortalama vektörüne ve $\Sigma_{i}$ varyans-kovaryans matrisine sahip $p$ boyutlu normal dağılım $N_{p}\left(\mu_{i}, \Sigma_{i}\right)$ olmak üzere $i=1,2, \ldots, k$ için $k$ tane bağımsız normal dağılıma sahip örneklem $X_{i 1}, X_{i 2}, \ldots, X_{i n_{i}} \sim N_{p}\left(\mu_{i}, \Sigma_{i}\right)$ olsun. Bu durumda $p$ tane bağıml değişkene sahip $k$ anakütle ortalama vektörünün eşitliği

$$
\begin{gathered}
\left.H_{0}: \mu_{1(p \times 1)}=\mu_{2}(p \times 1)=\cdots=\mu_{k}=\cdots \times 1\right) \\
H_{1}: \mu_{i}^{\prime} \text { lerden en az biri farklıdır. }
\end{gathered}
$$

biçimindeki hipotez ile ifade edilmektedir. Denklem 1'deki yokluk hipotezini sınamak için

$$
\begin{gathered}
W=\sum_{i=1}^{k} \sum_{j=1}^{n_{i}}\left(X_{i j}-\bar{X}_{i}\right)\left(X_{i j}-\bar{X}_{i}\right)^{\prime}=\sum_{i=1}^{k}\left(n_{i}-1\right) \hat{\Sigma}_{i} \\
B=\sum_{i=1}^{k} n_{i}\left(\bar{X}_{i}-\bar{X}\right)\left(\bar{X}_{i}-\bar{X}\right)^{\prime}
\end{gathered}
$$

biçimindeki grup içi ve gruplar arası kareler ve çarpımlar toplamı matrisleri dikkate alınmaktadır. Burada her bir gruba ait gözlem sayısı $n_{i}$ olmak üzere $i$. örneklemin $p \times 1$ boyutlu ortalamalar vektörü $\bar{X}_{i}$ ve genel ortalamalar vektörü ise $\bar{X}$ ile gösterilmektedir. Ayrıca $i$. örneklemin varyans-kovaryans matrisi

$$
\hat{\Sigma}_{i}=\frac{1}{\left(n_{i}-1\right)} \sum_{j=1}^{n_{i}}\left(X_{i j}-\bar{X}_{i}\right)\left(X_{i j}-\bar{X}_{i}\right)^{\prime}
$$

eşitliğindeki gibi hesaplanmaktadır. Böylece [3-6] tarafından önerilen test istatistikleri kullanılarak Denklem 1'de verilen yokluk hipotezi sınanmaktadır. MANOVA problemleri için gerekli olan varsayımlar sağlandığında ve bağımlı değişken sayısı gözlem sayısından daha küçük olduğu durumlarda [3-6] tarafindan önerilen test istatistikleri oldukça güçlü testlerdir. Ancak yüksek boyutlu veriler söz konusu 
olduğunda ise MANOVA test istatistikleri kullanılamamaktadır. $\mathrm{Bu}$ nedenle yeni yaklaşımların dikkate alınması gerekmektedir.

\section{Alternatif Test İstatistikleri}

\subsection{Yamada ve Himeno (2015) testi}

Yüksek boyutlu verilerde Denklem 1'de verilen yokluk hipotezini sınamak için [20] tarafından yeni bir test istatistiği önerilmiştir. [20], yüksek boyutlu verilerde homojenlik varsayımına ihtiyaç duymadan $k$ ortalamalar vektörünün eşitliğini test etmek için [16] tarafindan sunulan test istatistiğini

$$
T_{Y H}=\operatorname{tr}(B)-\sum_{i=1}^{k}\left(1-\frac{n_{i}}{N}\right) \operatorname{tr} \widehat{\Sigma}_{i}
$$

biçiminde yeniden tanımlamıştır. Böylece [20], Denklem 5'teki test istatistiğinin

$$
T_{Y H}^{*}=\frac{T_{Y H}}{\hat{\sigma}_{Y H}} \stackrel{d}{\rightarrow} N(0,1)
$$

biçiminde standart normal dağılıma yakınsadığını ifade etmektedir. $\mathrm{Bu}$ durumda $\operatorname{tr}\left(\widehat{\Sigma_{l} \Sigma_{J}}\right)=\operatorname{tr}\left(\hat{\Sigma}_{i} \hat{\Sigma}_{j}\right)$ ve

$$
\theta_{i}=\frac{1}{\left(n_{i}-1\right)} \sum_{j=1}^{n_{i}}\left(\left(X_{i j}-\bar{X}_{i}\right)^{\prime}\left(X_{i j}-\bar{X}_{i}\right)\right)^{2}
$$

için

$$
\widehat{\operatorname{tr}\left(\Sigma_{l}^{2}\right)}=\frac{\left(n_{i}-1\right)}{n_{i}\left(n_{i}-2\right)\left(n_{i}-3\right)}\left[\left\{\left(n_{i}-1\right)\left(n_{i}-2\right) \operatorname{tr} \widehat{\Sigma}_{i}^{2}\right\}+\left(\operatorname{tr} \widehat{\Sigma}_{i}\right)^{2}-n_{i} \theta_{i}\right]
$$

olmak üzere $\sigma_{Y H}^{2}$ '’n yansız bir tahmincisi

$$
\hat{\sigma}_{Y H}^{2}=2 \sum_{i=1}^{k}\left(1-\frac{n_{i}}{N}\right)^{2} \frac{n_{i}}{\left(n_{i}-1\right)} \widehat{\operatorname{tr}\left(\Sigma_{l}^{2}\right)}+2 \sum_{i \neq j}^{k} \frac{n_{i} n_{j}}{N^{2}} \operatorname{tr} \widehat{\left(\Sigma_{l} \Sigma_{J}\right)}
$$

şeklindedir. Burada $N=\sum_{i=1}^{k} n_{i}$ olarak hesaplanmaktadır. Dolayısıyla $\alpha$ anlamlılık düzeyi için $T_{Y H}^{*}$ test istatistiği standart normal dağılımın kritik değerinden daha büyük ise yokluk hipotezi reddedilmektedir [20].

\subsection{Zhou’ nun (2016) $\mathrm{L}^{2}$ norm testi}

Heterojenlik altında yüksek boyutlu MANOVA problemlerine ilişkin bir başka yaklaşım ise [21] tarafından sunulmuştur. [21], homojenlik varsayımı olmadan yüksek boyutlu ortalamalar vektörlerinin eşitliğini test etmek için $L^{2}$-norm yaklaşımına dayalı 
bir test istatistiği ortaya koymuştur. Öklid normu olarak da bilinen $L^{2}$ norm, iki nokta arasındaki en kısa uzaklığı ifade etmektedir. Bu durumda tek yönlü MANOVA probleminde normal dağılıma sahip $k$ grup için $L^{2}$ norm uzaklığına dayalı bir test istatistiği

$$
T_{Z}^{*}=\sum_{i=1}^{k} n_{i}\left\|\bar{X}_{i}-\bar{X}\right\|^{2}
$$

biçiminde tanımlanabilmektedir. Bu test istatistiği, ilgilenilen $k$ örneklemin ortalamalar vektörü ile bütün örneklemlerin ortalamalar vektörü arasındaki $L^{2}$ uzaklığına bağlı bir test istatistiğidir. Denklem 10'daki test istatistiğinin olasılık dağılımına yakınsamak için Welch-Satterthwaite ki-kare yaklaşımı kullanılmıştır. Dolayısıyla $\hat{\beta} \chi_{\hat{d}}^{2}$ değeri, $T_{Z}^{*}$ test istatistiği için kritik değer olarak belirlenmektedir. Bu durumda $i, j=1, \ldots, k$ için

$$
\left\{\begin{array}{cc}
a_{i i}=1-\frac{n_{i}}{N} & i=j \\
a_{i j}=-\frac{\sqrt{n_{i} n_{j}}}{N} & i \neq j
\end{array}\right.
$$

olmak üzere $\hat{\beta}$ ve $\hat{d}$ parametreleri sirasıyla

$$
\hat{\beta}=\frac{\sum_{i=1}^{k} a_{i i}^{2}\left[\frac{\left(n_{i}-1\right)^{2}}{\left(n_{i}-2\right)\left(n_{i}+1\right)}\left(\operatorname{tr} \widehat{\Sigma}_{i}^{2}-\frac{1}{\left(n_{i}-1\right)}\left(\operatorname{tr} \widehat{\Sigma}_{i}\right)^{2}\right)\right]+2 \sum_{i \neq j} a_{i j}^{2} \operatorname{tr}\left(\widehat{\Sigma}_{i} \widehat{\Sigma}_{j}\right)}{\sum_{i=1}^{k} a_{i i} \operatorname{tr} \hat{\Sigma}_{i}}
$$

ve

$$
\hat{d}=\frac{\sum_{i=1}^{k} a_{i i}^{2}\left[\frac{n_{i}\left(n_{i}-1\right)}{\left(n_{i}-2\right)\left(n_{i}+1\right)}\left(\left(\operatorname{tr} \widehat{\Sigma}_{i}\right)^{2}-\frac{2}{n_{i}} \operatorname{tr} \widehat{\Sigma}_{i}^{2}\right)\right]+2 \sum_{i \neq j} a_{i i} a_{j j}\left(\operatorname{tr} \widehat{\Sigma}_{i}\right)\left(\operatorname{tr} \widehat{\Sigma}_{j}\right)}{\sum_{i=1}^{k} a_{i i}^{2}\left[\frac{\left(n_{i}-1\right)^{2}}{\left(n_{i}-2\right)\left(n_{i}+1\right)}\left(\operatorname{tr} \hat{\Sigma}_{i}^{2}-\frac{1}{\left(n_{i}-1\right)}\left(\operatorname{tr} \hat{\Sigma}_{i}\right)^{2}\right)\right]+2 \sum_{i \neq j} a_{i j}^{2} \operatorname{tr}\left(\widehat{\Sigma}_{i} \hat{\Sigma}_{j}\right)}
$$

şeklinde hesaplanmaktadır. Böylece hesaplanan $T_{Z}^{*}$ test istatistiği $\hat{\beta} \chi_{\widehat{d}}^{2}$ kritik değerinden daha büyük ise yokluk hipotezi reddedilmektedir [21].

\subsection{Hu vd.nin (2017) testi}

Yüksek boyutlu verilerde ve homojenlik varsayımının sağlanmadığı durumlarda [12] tarafından önerilen test istatistiği, ikiden fazla grup ortalama vektörü için [22] tarafından genellenmiştir. İkiden fazla ortalama vektörün karşılaştırılması için Öklid uzaklık ölçüsüne dayalı olarak oluşturulan test istatistiği

$$
T_{H B W W}=\sum_{i<j}^{k}\left(\bar{X}_{i}-\bar{X}_{j}\right)^{\prime}\left(\bar{X}_{i}-\bar{X}_{j}\right)-(k-1) \sum_{i=1}^{k} \frac{\operatorname{tr} \hat{\Sigma}_{i}}{n_{i}}
$$

biçiminde tanımlanmaktadır. [22]'e göre Denklem 14'deki $T_{H B W W}$ test istatistiği 


$$
\frac{T_{H B W W}-E\left(T_{H B W W}\right)}{\sqrt{\operatorname{Var}\left(T_{H B W W}\right)}} \stackrel{d}{\rightarrow} N(0,1)
$$

olacak şekilde normal dağılıma yakınsamaktadır. Burada $E\left(T_{H B W W}\right)$ değeri

$$
E\left(T_{H B W W}\right)=\sum_{i<j}^{k}\left\|\mu_{i}-\mu_{j}\right\|^{2}
$$

şeklindedir. [12]'nin test istatistiğine paralel olarak $T_{H B W W}$ istatistiğinin tanımlanması için $\operatorname{Var}\left(T_{H B W W}\right)$ 'ın tahmin edilmesi gerekmektedir. Bu durumda $p \rightarrow \infty$ ve $N \rightarrow \infty$ için

$$
\begin{gathered}
\widehat{\operatorname{tr} \Sigma_{l}^{2}}=\frac{\left(n_{i}-1\right)^{2}}{\left(n_{i}+1\right)\left(n_{i}-2\right)}\left(\operatorname{tr} \widehat{\Sigma}_{i}^{2}-\frac{1}{n_{i}-1}\left(\operatorname{tr} \widehat{\Sigma}_{i}\right)^{2}\right) \\
\left.\operatorname{tr} \widehat{\left(\Sigma_{l} \Sigma_{J}\right.}\right)=\operatorname{tr} \widehat{\Sigma}_{i} \hat{\Sigma}_{j}
\end{gathered}
$$

olmak üzere minimum varyanslı yansız tahmincisi (UMVUE)

$$
\left.\left(\hat{\sigma}_{H B W W}\right)^{2}=\sum_{i=1}^{k} \frac{2(k-1)^{2}}{n_{i}\left(n_{i}-1\right)} \widehat{\operatorname{tr} \Sigma_{l}^{2}}+\sum_{i<j}^{k} \frac{4}{n_{i} n_{j}} \operatorname{tr} \widehat{\left(\Sigma_{l} \Sigma_{J}\right.}\right), \quad i \neq j \in\{1, \ldots, k\}
$$

şeklindedir. Dolayısıyla yokluk hipotezi ve bütün varsayımlar altında $p \rightarrow \infty$ ve $N \rightarrow \infty$ için test istatistiği

$$
T_{H B W W}^{*}=\frac{T_{H B W W}}{\hat{\sigma}_{H B W W}} \rightarrow N(0,1)
$$

olmaktadır. Denklem 20'deki $T_{H B W W}^{*}$ test istatistiği, $\alpha$ anlamlılık düzeyine göre standart normal dağılımın kritik değerinden daha büyük ise yokluk hipotezi reddedilmektedir. Ayrıca $k=2$ durumunda $T_{H B W W}$ test istatistiği [12]'nin iki değişkenli test istatistiğine dönüşmektedir [22].

\subsection{Cao vd.nin (2019) testi}

[12], varyans- kovaryans matrislerinin heterojenliği altında iki ortalama vektör arasındaki farkın eşitliğini test etmek için [11]'in sunduğu test istatistiğinden $\sum_{j=1}^{n_{i}} X_{i j}^{\prime} X_{i j}$ terimini çıkartarak yeni bir test istatistiği ortaya koymuştur. [23]'ün test istatistiği ise [12]'nin bir terim çıkarma düşüncesinin [16] tarafindan sunulan test istatistiğine uygulanmasına dayanmaktadır.

[16]'nın test istatistiğine [12]'nin $X_{i t}^{\prime} X_{i t}$ terimini çıkarma düşüncesi uygulandığında, [16]'nın test istatistiği 


$$
T_{C P H}=\sum_{i=1}^{k} \frac{N-n_{i}}{N\left(n_{i}-1\right)} \sum_{t \neq s}^{n_{i}} X_{i t}^{\prime} X_{i s}-\sum_{i \neq j}^{k} \frac{n_{i} n_{j}}{N} \bar{X}_{i}^{\prime} \bar{X}_{j}
$$

şeklinde yeniden yazılabilmektedir. Bu durumda test istatistiğinin asimptotik dağılımına yakınsamak için standart sapmasının tutarlı bir tahmincisinin belirlenmesi gerekmektedir. [23] tarafından [24] ile [22]'nin çalışmalarındaki tahmincilere göre iki farklı test istatistiği tanımlamıştır. [22]'nin çalışmasındaki tahmin edici dikkate alındığında standart sapmanın tutarlı bir tahmincisi

$$
\widetilde{\operatorname{tr}\left(\Sigma_{l}^{2}\right)}=\frac{\left(n_{i}-1\right)^{2}}{\left(n_{i}+1\right)\left(n_{i}-2\right)}\left[\operatorname{tr} \widehat{\Sigma}_{i}^{2}-\frac{1}{\left(n_{i}-1\right)}\left(\operatorname{tr} \widehat{\Sigma}_{i}\right)^{2}\right]
$$

olmak üzere

$$
\left.\tilde{\sigma}_{C P H}^{2}=\frac{2}{N^{2}}\left[\sum_{i=1}^{k} \frac{n_{i}\left(N-n_{i}\right)^{2}}{\left(n_{i}-1\right)} \widetilde{\operatorname{tr}\left(\Sigma_{l}^{2}\right)}+\sum_{i \neq j}^{k} n_{i} n_{j} \operatorname{tr} \overline{\left(\Sigma_{l} \Sigma_{J}\right.}\right)\right]
$$

biçiminde elde edilmektedir. Böylece test istatistiğinin asimptotik dağılımı

$$
T_{C P H}^{*}=\frac{T_{C P H}}{\tilde{\sigma}_{C P H}}
$$

olacak şeklinde standart normal dağılıma yakınsamaktadır [23]. Bu durumda $\alpha$ anlamlılık düzeyinde Denklem 24'teki $T_{C P H}^{*}$ test istatistiği standart normal dağılımın kritik değerinden daha büyük ise yokluk hipotezi reddedilmektedir.

\section{Bulgular}

$\mathrm{Bu}$ çalışmanın amacı; yüksek boyutlu verilerde ve homojenlik varsayımının sağlanmadığı durumlarda, ortalama vektörlerin eşitliğini sınamak için önerilen test istatistiklerinin performanslarını farklı varyans-kovaryans modellerine göre karşılaştırmaktır. Bu amaçla yüksek boyutlu verilerde MANOVA problemleri için [20], [21], [22] ve [23] tarafından önerilen test istatistikleri bir simülasyon çalışması ile karşılaştırılmıştır. Test istatistiklerinin performanslarını karşılaştırmak için ilk olarak çok değişkenli normal dağılıma sahip rassal gözlemler türetilmiştir. Homojen olmayan varyans-kovaryans matrisleri altında test istatistiklerinin ortaya koyduğu I. tip hata yapma olasılıklarını belirlemek için üç farklı model kullanılmıştır:

1. Model: $\Sigma_{i}=i * I_{p} \quad i=1, \ldots, k$

2. Model: $\Sigma_{i}=\sigma_{j s}=\left\{\begin{array}{cc}u_{j s} & j=s \\ 0 & j \neq s\end{array}\right.$

$$
\begin{gathered}
i=1 \Rightarrow U(0,2) \quad i=3 \Rightarrow U(0.5,2.5) \\
u_{j s} \sim U(l, m) \quad i=2 \Rightarrow U(1,4) \quad i=4 \Rightarrow U(3,6)
\end{gathered}
$$

3. Model: $\Sigma_{i}=\sigma_{j s}=\left\{\begin{array}{cc}1 & j=s \\ (-1)^{j+s} \frac{i * \rho}{s} & j<s\end{array} \quad i=1, \ldots, k ; \quad \rho=0,05\right.$ 
Burada $U(l, m) ; l$ ve $m$ parametreli Uniform dağılımı, $J_{p} ; p$ boyutlu 1'lerden oluşan vektörü ve $I_{p}$ ise $p$ boyutlu birim matrisi temsil etmektedir. Böylece hem heterojenlik hem de farklı kovaryans yapıları altında test istatistiklerinin performansları araştırılmıştır. Çok değişkenli normal dağılım varsayımı altında her bir test istatistiğinin deneysel olasılık $(p)$ değerleri hesaplanmıştır. Elde edilen olasılık değerleri $\alpha$ anlamlılık düzeyi ile karşılaştırılmış ve olasıllk değerinden daha büyük olan $\alpha$ değerleri için yokluk hipotezi reddedilmiştir. Yapılan tekrar (iterasyon) sayısı $N^{*}$ olmak üzere bu işlemler $N^{*}$ kez tekrar edilmiştir. Böylece test istatistiklerinin her biri için elde edilen red sayıları toplaminın yapılan iterasyon sayısına oranlanması ile I. tip hata yapma olasılıkları belirlenmiştir.

Simülasyon çalışmasında bütün test istatistikleri için 5000 iterasyon gerçekleştirilmiştir. Her bir test istatistiği için $k=3$ ve $k=4$ olmak üzere iki farklı grup düzeyi ve her bir grup için $p=50,100,200,300,500$ olacak şekilde beş farklı değişken yapısı dikkate alınmıştır. Ayrıca anlamlılık düzeyi $\alpha=0,05$ olarak belirlenirken, test istatistiklerinin algoritmalarını oluşturmak için RStudio programı kullanılmıştır.

Üç farklı varyans-kovaryans modeli için $k=3$ durumunda $p=50,100,200,300,500$ değerlerine ve $n_{i}$ gözlem sayılarına göre test istatistiklerine ait deneysel hata yapma olasılıklarının grafikleri Şekil 1'de yer almaktadır.
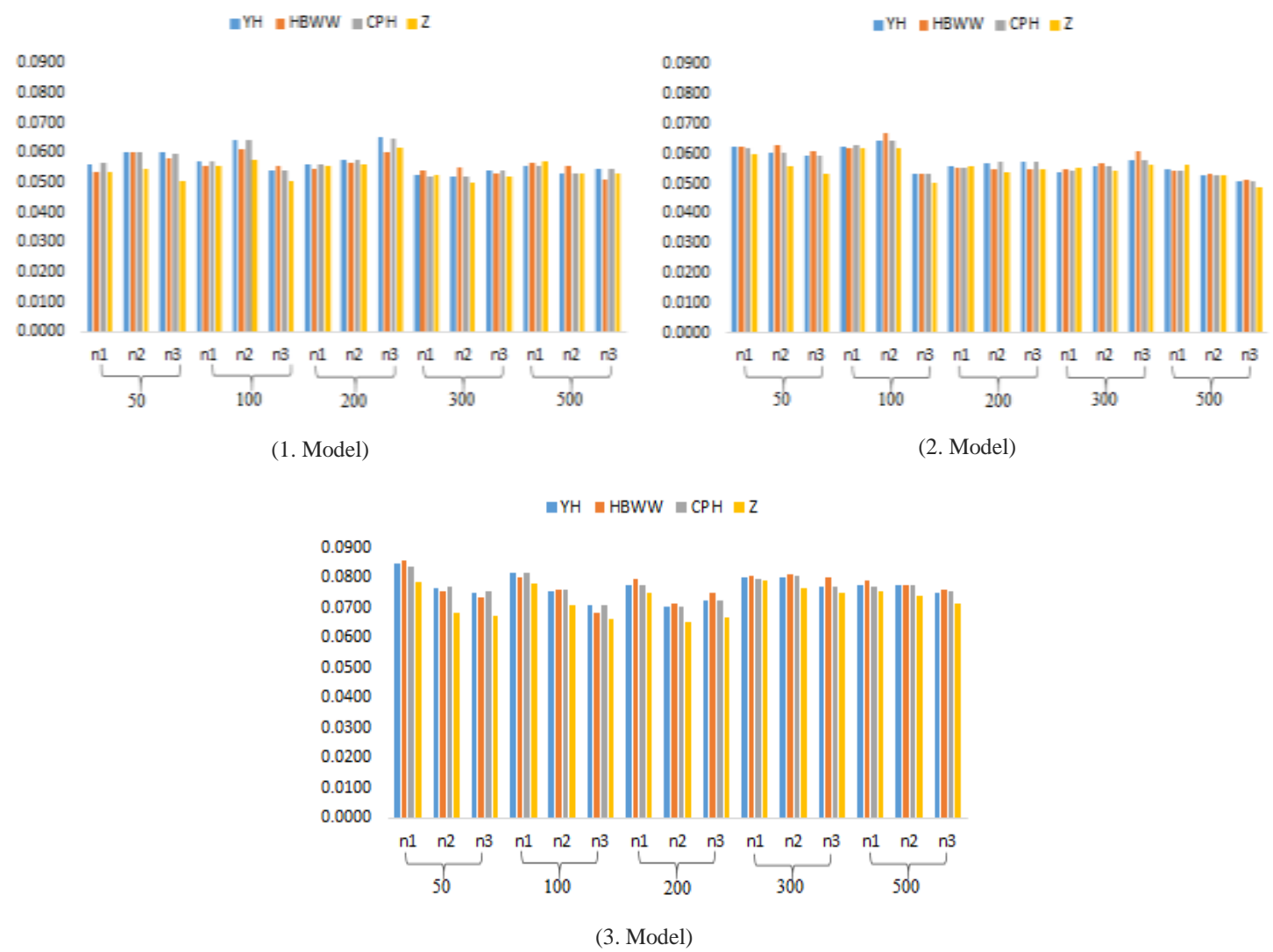

Şekil 1: $\mathrm{k}=3$ durumunda üç farklı varyans-kovaryans modeline göre test istatistiklerinin I. tip hata yapma olasilıkları

Ayrica her bir varyans-kovaryans modeli için $k=3$ grup sayıs ile $p=$ $50,100,200,300,500$ değerlerine göre test istatistiklerine ait deneysel hata yapma olasılıkları Tablo 1'de verilmiştir. 
Tablo 1. $\mathrm{k}=3$ durumunda üç farklı varyans-kovaryans modeline göre test istatistiklerinin I. tip hata yapma olasılikları

\begin{tabular}{|c|c|c|c|c|c|c|}
\hline$\Sigma_{i}$ & $p$ & $\left(\boldsymbol{n}_{\boldsymbol{i}}\right)$ & $T_{Y H}^{*}$ & $T_{H B W W}^{*}$ & $T_{C P H}^{*}$ & $T_{Z}^{*}$ \\
\hline \multirow{15}{*}{ 1. Model } & \multirow{3}{*}{50} & $n_{1}$ & 0.0562 & 0.0534 & 0.0566 & 0.0536 \\
\hline & & $n_{2}$ & 0.0602 & 0.0602 & 0.0600 & 0.0546 \\
\hline & & $n_{3}$ & 0.0600 & 0.0580 & 0.0596 & 0.0504 \\
\hline & \multirow{3}{*}{100} & $n_{1}$ & 0.0570 & 0.0556 & 0.0572 & 0.0556 \\
\hline & & $n_{2}$ & 0.0640 & 0.0610 & 0.0640 & 0.0574 \\
\hline & & $n_{3}$ & 0.0540 & 0.0554 & 0.0542 & 0.0504 \\
\hline & \multirow{3}{*}{200} & $n_{1}$ & 0.0562 & 0.0546 & 0.0560 & 0.0558 \\
\hline & & $n_{2}$ & 0.0578 & 0.0564 & 0.0578 & 0.0560 \\
\hline & & $n_{3}$ & 0.0650 & 0.0600 & 0.0648 & 0.0614 \\
\hline & \multirow{3}{*}{300} & $n_{1}$ & 0.0526 & 0.0540 & 0.0522 & 0.0524 \\
\hline & & $n_{2}$ & 0.0518 & 0.0548 & 0.0520 & 0.0498 \\
\hline & & $n_{3}$ & 0.0538 & 0.0530 & 0.0540 & 0.0520 \\
\hline & \multirow{3}{*}{500} & $n_{1}$ & 0.0558 & 0.0568 & 0.0556 & 0.0572 \\
\hline & & $n_{2}$ & 0.0532 & 0.0556 & 0.0530 & 0.0528 \\
\hline & & $n_{3}$ & 0.0544 & 0.0512 & 0.0546 & 0.0528 \\
\hline \multirow{15}{*}{ 2. Model } & \multirow{3}{*}{50} & $n_{1}$ & 0.0622 & 0.0626 & 0.0620 & 0.0596 \\
\hline & & $n_{2}$ & 0.0602 & 0.0630 & 0.0602 & 0.0558 \\
\hline & & $n_{3}$ & 0.0594 & 0.0606 & 0.0594 & 0.0532 \\
\hline & \multirow{3}{*}{100} & $n_{1}$ & 0.0622 & 0.0618 & 0.0630 & 0.0620 \\
\hline & & $n_{2}$ & 0.0644 & 0.0670 & 0.0644 & 0.0618 \\
\hline & & $n_{3}$ & 0.0534 & 0.0534 & 0.0534 & 0.0504 \\
\hline & \multirow{3}{*}{200} & $n_{1}$ & 0.0556 & 0.0552 & 0.0552 & 0.0558 \\
\hline & & $n_{2}$ & 0.0570 & 0.0548 & 0.0572 & 0.0538 \\
\hline & & $n_{3}$ & 0.0572 & 0.0548 & 0.0574 & 0.0548 \\
\hline & \multirow{3}{*}{300} & $n_{1}$ & 0.0540 & 0.0546 & 0.0542 & 0.0554 \\
\hline & & $n_{2}$ & 0.0556 & 0.0568 & 0.0558 & 0.0542 \\
\hline & & $n_{3}$ & 0.0578 & 0.0610 & 0.0580 & 0.0562 \\
\hline & \multirow{3}{*}{500} & $n_{1}$ & 0.0546 & 0.0542 & 0.0544 & 0.0564 \\
\hline & & $n_{2}$ & 0.0528 & 0.0532 & 0.0528 & 0.0526 \\
\hline & & $n_{3}$ & 0.0506 & 0.0514 & 0.0506 & 0.0488 \\
\hline \multirow{15}{*}{ 3. Model } & \multirow{3}{*}{50} & $n_{1}$ & 0.0846 & 0.0858 & 0.0838 & 0.0784 \\
\hline & & $n_{2}$ & 0.0764 & 0.0754 & 0.0768 & 0.0684 \\
\hline & & $n_{3}$ & 0.0750 & 0.0734 & 0.0754 & 0.0672 \\
\hline & \multirow{3}{*}{100} & $n_{1}$ & 0.0816 & 0.0802 & 0.0814 & 0.0778 \\
\hline & & $n_{2}$ & 0.0756 & 0.0758 & 0.0760 & 0.0706 \\
\hline & & $n_{3}$ & 0.0708 & 0.0682 & 0.0710 & 0.0660 \\
\hline & \multirow{3}{*}{200} & $n_{1}$ & 0.0776 & 0.0794 & 0.0774 & 0.0748 \\
\hline & & $n_{2}$ & 0.0702 & 0.0714 & 0.0702 & 0.0650 \\
\hline & & $n_{3}$ & 0.0726 & 0.0750 & 0.0724 & 0.0668 \\
\hline & \multirow{3}{*}{300} & $n_{1}$ & 0.0800 & 0.0804 & 0.0796 & 0.0788 \\
\hline & & $n_{2}$ & 0.0802 & 0.0812 & 0.0806 & 0.0766 \\
\hline & & $n_{3}$ & 0.0772 & 0.0802 & 0.0772 & 0.0750 \\
\hline & \multirow{3}{*}{500} & $n_{1}$ & 0.0774 & 0.0792 & 0.0770 & 0.0756 \\
\hline & & $n_{2}$ & 0.0776 & 0.0776 & 0.0774 & 0.0740 \\
\hline & & $n_{3}$ & 0.0750 & 0.0760 & 0.0756 & 0.0714 \\
\hline$n_{1}=$ & $0,15,25)$ & & $(20,30$ & & $n_{3}=(3$ & 75) \\
\hline
\end{tabular}

Şekil 1 ve Tablo 1 incelendiğinde $k=3$ için birinci ve ikinci modele göre test istatistiklerinin I. tip hata oranları $\% 5$ ile $\% 6$ civarında elde edilirken, üçüncü modelde ise $\% 7$ 'den daha fazla olduğu gözlemlenmiştir. Bağımlı değişken sayısı arttıkça test istatistikleri için elde edilen deneysel hata olasılıklarının da nominal anlamlılık düzeyine yaklaştığı gözlemlenmiştir. Bütün deneysel koşullar dikkate alındığında $T_{Z}^{*}$ test istatistiği, diğer test istatistiklerine göre daha düşük I. tip hata yapma olasılığı ortaya koymaktadır. $T_{C P H}^{*}$ ve $T_{Y H}^{*}$ test istatistikleri genel olarak birbirlerine yakın değerler 
ortaya koyarken, $T_{H B W W}^{*}$ test istatistiği ise varyans-kovaryans modeline göre farklılık göstermektedir. Birinci model için $T_{H B W W}^{*}$ test istatistiği genel olarak $T_{C P H}^{*}$ ve $T_{Y H}^{*}$ 'a göre daha düşük değerler ortaya koymuştur. Ancak ikinci ve üçüncü modelde ise en yüksek deneysel hata yapma olasılıkları $T_{H B W W}^{*}$ test istatistiğinden elde edilmiştir.

Her bir varyans-kovaryans modeli için $k=4$ ve $p=50,100,200,300,500$ değerlerine göre test istatistiklerinin deneysel hata yapma olasılıkları Tablo 2'de verilmiştir.

Tablo 2. $\mathrm{k}=4$ durumunda üç farklı varyans-kovaryans modeline göre test istatistiklerinin I. tip hata yapma olasılıkları

\begin{tabular}{|c|c|c|c|c|c|c|}
\hline$\Sigma_{i}$ & $p$ & $\left(\boldsymbol{n}_{\boldsymbol{i}}\right)$ & $T_{Y H}^{*}$ & $\boldsymbol{T}_{H B W W}^{*}$ & $T_{C P H}^{*}$ & $\boldsymbol{T}_{Z}^{*}$ \\
\hline \multirow{15}{*}{ 1. Model } & \multirow{3}{*}{50} & $n_{1}$ & 0.0558 & 0.0534 & 0.0498 & 0.0524 \\
\hline & & $n_{2}$ & 0.0594 & 0.0572 & 0.0540 & 0.0544 \\
\hline & & $n_{3}$ & 0.0592 & 0.0546 & 0.0550 & 0.0546 \\
\hline & \multirow{3}{*}{100} & $n_{1}$ & 0.0558 & 0.0564 & 0.0512 & 0.0542 \\
\hline & & $n_{2}$ & 0.0578 & 0.0572 & 0.0530 & 0.0550 \\
\hline & & $n_{3}$ & 0.0530 & 0.0536 & 0.0484 & 0.0490 \\
\hline & \multirow{3}{*}{200} & $n_{1}$ & 0.0556 & 0.0576 & 0.0510 & 0.0552 \\
\hline & & $n_{2}$ & 0.0532 & 0.0490 & 0.0476 & 0.0518 \\
\hline & & $n_{3}$ & 0.0532 & 0.0554 & 0.0494 & 0.0514 \\
\hline & \multirow{3}{*}{300} & $n_{1}$ & 0.0536 & 0.0514 & 0.0472 & 0.0532 \\
\hline & & $n_{2}$ & 0.0526 & 0.0520 & 0.0480 & 0.0512 \\
\hline & & $n_{3}$ & 0.0584 & 0.0602 & 0.0520 & 0.0550 \\
\hline & \multirow{3}{*}{500} & $n_{1}$ & 0.0476 & 0.0496 & 0.0422 & 0.0494 \\
\hline & & $n_{2}$ & 0.0488 & 0.0502 & 0.0442 & 0.0486 \\
\hline & & $n_{3}$ & 0.0496 & 0.0512 & 0.0440 & 0.0476 \\
\hline \multirow{15}{*}{ 2. Model } & \multirow{3}{*}{50} & $n_{1}$ & 0.0602 & 0.0562 & 0.0534 & 0.0560 \\
\hline & & $n_{2}$ & 0.0604 & 0.0554 & 0.0544 & 0.0558 \\
\hline & & $n_{3}$ & 0.0584 & 0.0588 & 0.0518 & 0.0530 \\
\hline & \multirow{3}{*}{100} & $n_{1}$ & 0.0570 & 0.0566 & 0.0492 & 0.0544 \\
\hline & & $n_{2}$ & 0.0538 & 0.0526 & 0.0470 & 0.0520 \\
\hline & & $n_{3}$ & 0.0568 & 0.0540 & 0.0486 & 0.0524 \\
\hline & \multirow{3}{*}{200} & $n_{1}$ & 0.0526 & 0.0550 & 0.0444 & 0.0518 \\
\hline & & $n_{2}$ & 0.0538 & 0.0476 & 0.0474 & 0.0522 \\
\hline & & $n_{3}$ & 0.0534 & 0.0490 & 0.0472 & 0.0512 \\
\hline & \multirow{3}{*}{300} & $n_{1}$ & 0.0556 & 0.0540 & 0.0496 & 0.0566 \\
\hline & & $n_{2}$ & 0.0508 & 0.0500 & 0.0434 & 0.0494 \\
\hline & & $n_{3}$ & 0.0540 & 0.0536 & 0.0478 & 0.0536 \\
\hline & \multirow{3}{*}{500} & $n_{1}$ & 0.0488 & 0.0540 & 0.0432 & 0.0506 \\
\hline & & $n_{2}$ & 0.0454 & 0.0506 & 0.0404 & 0.0450 \\
\hline & & $n_{3}$ & 0.0536 & 0.0530 & 0.0472 & 0.0520 \\
\hline \multirow{15}{*}{ 3. Model } & \multirow{3}{*}{50} & $n_{1}$ & 0.0806 & 0.0812 & 0.0772 & 0.0756 \\
\hline & & $n_{2}$ & 0.0746 & 0.0750 & 0.0732 & 0.0694 \\
\hline & & $n_{3}$ & 0.0690 & 0.0678 & 0.0670 & 0.0628 \\
\hline & \multirow{3}{*}{100} & $n_{1}$ & 0.0778 & 0.0774 & 0.0750 & 0.0750 \\
\hline & & $n_{2}$ & 0.0738 & 0.0728 & 0.0714 & 0.0670 \\
\hline & & $n_{3}$ & 0.0708 & 0.0714 & 0.0686 & 0.0650 \\
\hline & \multirow{3}{*}{200} & $n_{1}$ & 0.0764 & 0.0796 & 0.0732 & 0.0742 \\
\hline & & $n_{2}$ & 0.0742 & 0.0732 & 0.0714 & 0.0692 \\
\hline & & $n_{3}$ & 0.0698 & 0.0688 & 0.0670 & 0.0646 \\
\hline & \multirow{3}{*}{300} & $n_{1}$ & 0.0770 & 0.0806 & 0.0740 & 0.0756 \\
\hline & & $n_{2}$ & 0.0698 & 0.0702 & 0.0682 & 0.0670 \\
\hline & & $n_{3}$ & 0.0760 & 0.0764 & 0.0738 & 0.0716 \\
\hline & \multirow{3}{*}{500} & $n_{1}$ & 0.0794 & 0.0878 & 0.0774 & 0.0794 \\
\hline & & $n_{2}$ & 0.0712 & 0.0746 & 0.0694 & 0.0686 \\
\hline & & $n_{3}$ & 0.0656 & 0.0698 & 0.0640 & 0.0636 \\
\hline \multicolumn{2}{|c|}{$n_{1}=(10,15,25,30)$} & \multicolumn{3}{|c|}{$n_{2}=(20,30,50,60)$} & $n_{3}=(30$ & $5,90)$ \\
\hline
\end{tabular}


Ayrıca üç farklı varyans-kovaryans modeli için $k=4$ durumunda $p=$ $50,100,200,300,500$ değerlerine ve $n_{i}$ gözlem sayılarına göre test istatistiklerine ait deneysel hata yapma olasılıkları Şekil 2'de yer almaktadır.
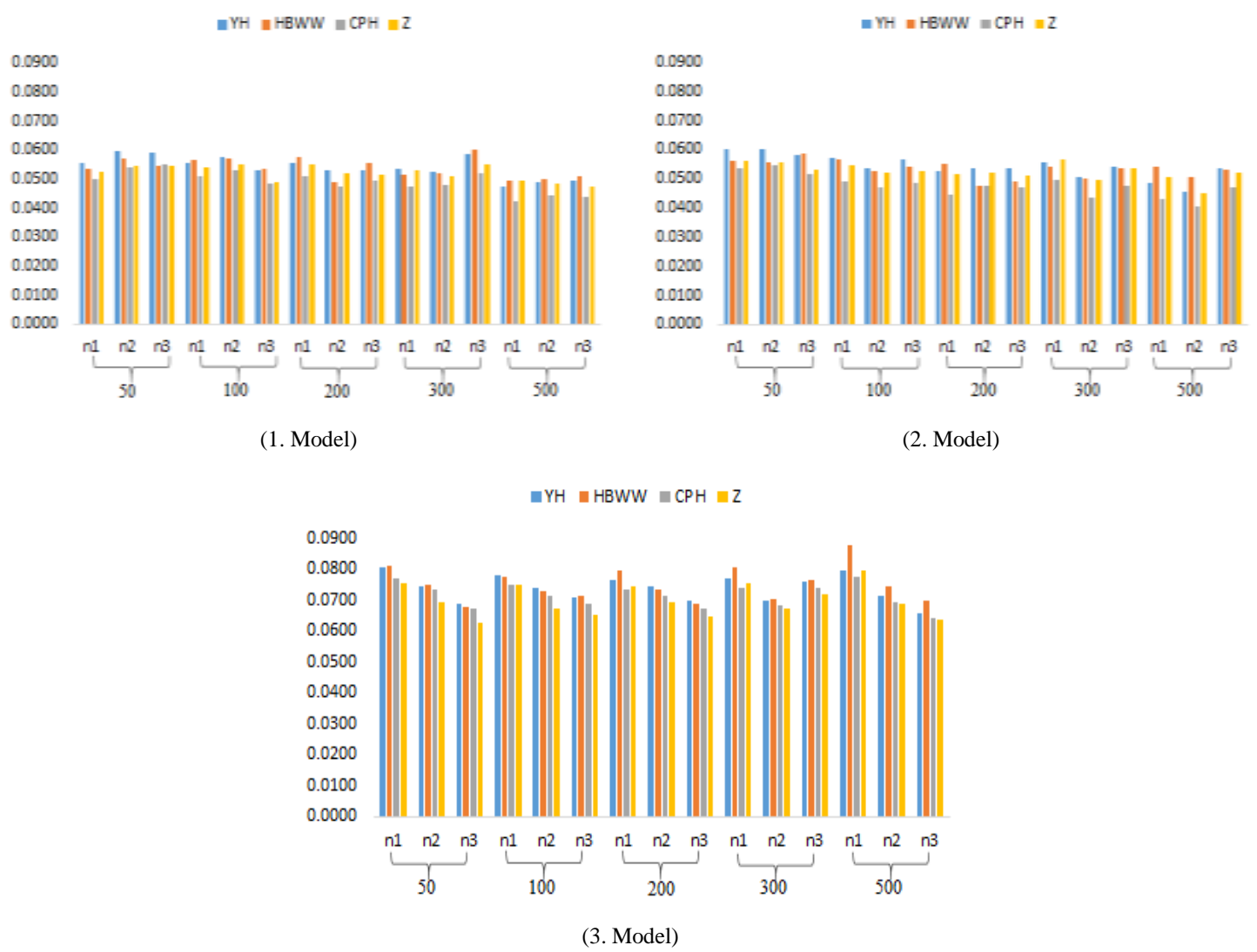

Şekil 2: $\mathrm{k}=4$ durumunda üç farklı varyans-kovaryans modeline göre test istatistiklerinin I. tip hata yapma olasılıkları

$k=4$ için simülasyon sonuçlarını gösteren Tablo 2 incelendiğinde ise, $k=3$ durumuna göre I. tip hata oranlarının nominal anlamlılık düzeyine daha yakın olduğu gözlemlenmiştir. Üç model için elde edilen sonuçlara göre genel olarak $T_{C P H}^{*}$ ve $T_{Z}^{*}$ test istatistikleri daha düşük deneysel hata yapma olasılıkları ortaya koymuştur. Ayrıca birinci ve ikinci model de $T_{H B W W}^{*}$ test istatistiğinin performans $T_{Y H}^{*}$ 'dan daha iyi olduğu görülürken, üçüncü modelde ise en kötü performans $T_{H B W W}^{*}$ test istatistiğinden elde edilmiştir. Bu durumda $k=4$ için tek bir varyans-kovaryans modeline göre $T_{H B W W}^{*}$ test istatistiğinin performansının $T_{Y H}^{*}$ 'a göre daha yüksek olduğu gözlemlenmiştir.

Simülasyon çalışması sonucunda elde edilen deneysel I. tip hata yapma olasılıklarına $(\hat{\alpha})$ göre test istatistiklerinin performanslarını belirlemek için [25], [26] ve [27] tarafından kullanılan "Ortalama Mutlak Tutarsızlık (AAD)" değeri hesaplanmıştır. Farklı deneysel koşullara göre elde edilen I. tip hata yapma olasılıkları $(\hat{\alpha})$ için AAD değeri

$$
A A D=\frac{1}{\widetilde{N}} \sum_{t=1}^{\widetilde{N}}\left(\hat{\alpha}_{t}-\alpha\right)
$$


biçiminde hesaplanmaktadır. AAD değeri düşük olan test istatistiğinin, daha iyi bir performans gösterdiği ifade edilmektedir. Tüm durumlar için elde edilen AAD değerleri Tablo 3'te yer almaktadır.

Tablo 3. Test istatistiklerine ait AAD değerleri

\begin{tabular}{|c|c|c|c|c|c|}
\hline Grup Sayısı & $\begin{array}{c}\text { Kovaryans } \\
\text { Modeli }\end{array}$ & $T_{Y H}^{*}$ & $T_{H B W W}^{*}$ & $T_{C P H}^{*}$ & $T_{Z}^{*}$ \\
\hline \multirow{4}{*}{$k=3$} & 1. Model & 0.6800 & 0.6000 & 0.6773 & 0.4173 \\
\hline & 2.Model & 0.7133 & 0.7627 & 0.7200 & 0.5547 \\
\hline & 3.Model & 2.6787 & 2.7280 & 2.6787 & 2.2427 \\
\hline & Genel: & 1.3573 & 1.3636 & 1.3587 & 1.0716 \\
\hline \multirow{4}{*}{$k=4$} & 1.Model & 0.4773 & 0.4120 & 0.3027 & 0.2920 \\
\hline & 2.Model & 0.5080 & 0.3813 & 0.3613 & 0.3147 \\
\hline & 3.Model & 2.3733 & 2.5107 & 2.1387 & 1.9907 \\
\hline & Genel: & 1.1196 & 1.1013 & 0.9342 & 0.8658 \\
\hline
\end{tabular}

Ayrıca $k=3$ ve $k=4$ durumunda üç farklı varyans-kovaryans modeli için hesaplanan AAD değerlerinin grafiği Şekil 3 'te gösterilmiştir.
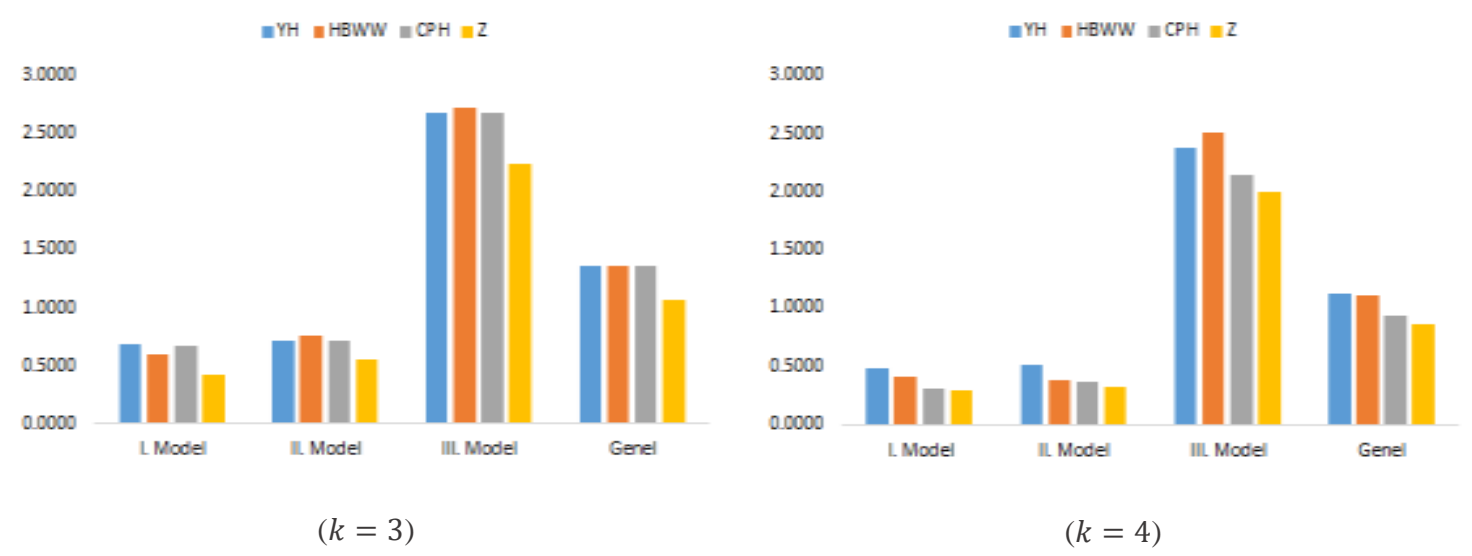

Şekil 3: $\mathrm{k}=3$ ve $\mathrm{k}=4$ durumunda üç farklı varyans-kovaryans modeline göre elde edilen AAD değerleri

Tablo 3 ve Şekil 3'e göre $k=3$ ve $k=4$ durumlarında bütün modellere göre en düşük $\mathrm{AAD}$ değeri $T_{Z}^{*}$ test istatistiğinden elde edilmiştir. $k=3$ için $T_{Y H}^{*}$ ve $T_{C P H}^{*}$ test istatistiklerinin AAD değerleri oldukça yakın çıkmaktadır. Ancak $k=4$ olduğunda ise $T_{C P H}^{*}$ test istatistiğinin performansının $T_{Y H}^{*}$ 'a göre daha iyi olduğu söylenebilir. Ayrıca bütün modellerin I. tip hata yapma olasılıkları toplamına göre hesaplanan genel AAD değerleri incelendiğinde, $k=3$ için $T_{H B W W}^{*}$ test istatistiğinin AAD değeri $T_{Y H}^{*}$ 'a göre daha yüksektir. Dolayısıyla $k=3$ için $T_{H B W W}^{*}$ test istatistiğinin performansı daha düşüktür. Ancak $k=4$ durumunda $T_{H B W W}^{*}$ test istatistiğinin performansının $T_{Y H}^{*}$ 'a göre daha yüksek olduğu görülmektedir. $\mathrm{Bu}$ durum grup sayısı arttıkça $T_{H B W W}^{*}$ test istatistiğinin performansının varyans-kovaryans modelinden daha az etkilendiğini göstermektedir.

Çalışmanın son aşamasında ise üç farklı varyans-kovaryans modeli için test istatistiklerinin güç değerleri hesaplanmıştır. Güç değerlerinin belirlenmesi için alternatif hipotez altında $\mu_{1}=0, \mu_{2}=(-1)^{i} *\left(b_{1}, \ldots, b_{p}\right)^{\prime}$ ve $b_{1} \sim U(0, t), \mu_{3}=-\mu_{2}$, $\mu_{4}=2 \mu_{2}$ seçilmiştir. $k=3$ için birinci ve ikinci modelde $t=0.15$, üçüncü modelde 
$t=0.20$ olarak alınmıştır. $k=4$ durumunda ise birinci ve ikinci modelde $t=0.10$, üçüncü modelde $t=0.13$ olarak alınmıştır. Böylece alternatif hipotez altında test istatistiklerinin güç değerleri elde edilmiştir. $k=3$ ve $k=4$ için üç farklı modele göre elde edilen güç değerleri sırasıyla Tablo 4 ve Tablo 5'te yer almaktadır.

Tablo 4. $\mathrm{k}=3$ durumunda üç farklı varyans-kovaryans modeline göre test istatistiklerinin güç değerleri

\begin{tabular}{|c|c|c|c|c|c|c|}
\hline$\Sigma_{i}$ & $\boldsymbol{p}$ & $\left(\boldsymbol{n}_{\boldsymbol{i}}\right)$ & $T_{Y H}^{*}$ & $T_{H B W W}^{*}$ & $\boldsymbol{T}_{\mathrm{CPH}}^{*}$ & $\boldsymbol{T}_{Z}^{*}$ \\
\hline \multirow{15}{*}{ 1. Model } & \multirow{3}{*}{50} & $n_{1}$ & 0.1606 & 0.1408 & 0.1616 & 0.1498 \\
\hline & & $n_{2}$ & 0.3034 & 0.2586 & 0.3038 & 0.2904 \\
\hline & & $n_{3}$ & 0.4812 & 0.4042 & 0.4810 & 0.4588 \\
\hline & \multirow{3}{*}{100} & $n_{1}$ & 0.2004 & 0.1702 & 0.2016 & 0.1970 \\
\hline & & $n_{2}$ & 0.4384 & 0.3688 & 0.4386 & 0.4252 \\
\hline & & $n_{3}$ & 0.6792 & 0.5908 & 0.6794 & 0.6626 \\
\hline & \multirow{3}{*}{200} & $n_{1}$ & 0.2868 & 0.2456 & 0.2876 & 0.2864 \\
\hline & & $n_{2}$ & 0.6542 & 0.5576 & 0.6542 & 0.6456 \\
\hline & & $n_{3}$ & 0.8862 & 0.8104 & 0.8858 & 0.8802 \\
\hline & \multirow{3}{*}{300} & $n_{1}$ & 0.3358 & 0.2784 & 0.3364 & 0.3370 \\
\hline & & $n_{2}$ & 0.7376 & 0.6410 & 0.7382 & 0.7318 \\
\hline & & $n_{3}$ & 0.9468 & 0.8924 & 0.9466 & 0.9454 \\
\hline & \multirow{3}{*}{500} & $n_{1}$ & 0.4728 & 0.3924 & 0.4732 & 0.4766 \\
\hline & & $n_{2}$ & 0.9074 & 0.8356 & 0.9074 & 0.9062 \\
\hline & & $n_{3}$ & 0.9966 & 0.9854 & 0.9966 & 0.9962 \\
\hline \multirow{15}{*}{ 2. Model } & \multirow{3}{*}{50} & $n_{1}$ & 0.1616 & 0.1352 & 0.1610 & 0.1562 \\
\hline & & $n_{2}$ & 0.3198 & 0.2458 & 0.3194 & 0.3054 \\
\hline & & $n_{3}$ & 0.5150 & 0.3996 & 0.5148 & 0.4960 \\
\hline & \multirow{3}{*}{100} & $n_{1}$ & 0.2192 & 0.1686 & 0.2176 & 0.2156 \\
\hline & & $n_{2}$ & 0.5010 & 0.3808 & 0.5016 & 0.4904 \\
\hline & & $n_{3}$ & 0.7416 & 0.6026 & 0.7408 & 0.7302 \\
\hline & \multirow{3}{*}{200} & $n_{1}$ & 0.3078 & 0.2348 & 0.3062 & 0.3068 \\
\hline & & $n_{2}$ & 0.6928 & 0.5584 & 0.6938 & 0.6882 \\
\hline & & $n_{3}$ & 0.9172 & 0.8076 & 0.9170 & 0.9138 \\
\hline & \multirow{3}{*}{300} & $n_{1}$ & 0.3592 & 0.2670 & 0.3588 & 0.3626 \\
\hline & & $n_{2}$ & 0.7874 & 0.6324 & 0.7858 & 0.7834 \\
\hline & & $n_{3}$ & 0.9666 & 0.8842 & 0.9666 & 0.9650 \\
\hline & \multirow{3}{*}{500} & $n_{1}$ & 0.5018 & 0.3736 & 0.5050 & 0.5116 \\
\hline & & $n_{2}$ & 0.9404 & 0.8352 & 0.9404 & 0.9396 \\
\hline & & $n_{3}$ & 0.9992 & 0.9850 & 0.9992 & 0.9990 \\
\hline \multirow{15}{*}{ 3. Model } & \multirow{3}{*}{50} & $n_{1}$ & 0.2724 & 0.2180 & 0.2710 & 0.2602 \\
\hline & & $n_{2}$ & 0.4872 & 0.3772 & 0.4880 & 0.4656 \\
\hline & & $n_{3}$ & 0.6728 & 0.5551 & 0.6726 & 0.6516 \\
\hline & \multirow{3}{*}{100} & $n_{1}$ & 0.3100 & 0.2480 & 0.3100 & 0.3046 \\
\hline & & $n_{2}$ & 0.5726 & 0.4566 & 0.5728 & 0.5552 \\
\hline & & $n_{3}$ & 0.7656 & 0.6478 & 0.7658 & 0.7506 \\
\hline & \multirow{3}{*}{200} & $n_{1}$ & 0.3782 & 0.3086 & 0.3780 & 0.3730 \\
\hline & & $n_{2}$ & 0.6676 & 0.5572 & 0.6676 & 0.6564 \\
\hline & & $n_{3}$ & 0.8574 & 0.7466 & 0.8576 & 0.8472 \\
\hline & \multirow{3}{*}{300} & $n_{1}$ & 0.3832 & 0.3036 & 0.3838 & 0.3804 \\
\hline & & $n_{2}$ & 0.6722 & 0.5570 & 0.6724 & 0.6604 \\
\hline & & $n_{3}$ & 0.8866 & 0.7850 & 0.8870 & 0.8760 \\
\hline & \multirow{3}{*}{500} & $n_{1}$ & 0.4446 & 0.3528 & 0.4440 & 0.4414 \\
\hline & & $n_{2}$ & 0.7720 & 0.6490 & 0.7722 & 0.7630 \\
\hline & & $n_{3}$ & 0.9410 & 0.8648 & 0.9414 & 0.9366 \\
\hline \multicolumn{2}{|c|}{$n_{1}=(10,15,25)$} & \multicolumn{3}{|c|}{$n_{2}=(20,30,50)$} & \multicolumn{2}{|c|}{$n_{3}=(30,45,75)$} \\
\hline
\end{tabular}


Tablo 5. $\mathrm{k}=4$ durumunda üç farklı varyans-kovaryans modeline göre test istatistiklerinin güç değerleri

\begin{tabular}{|c|c|c|c|c|c|c|}
\hline$\Sigma_{i}$ & $p$ & $\left(\boldsymbol{n}_{\boldsymbol{i}}\right)$ & $T_{Y H}^{*}$ & $T_{H B W W}^{*}$ & $\boldsymbol{T}_{C P H}^{*}$ & $T_{Z}^{*}$ \\
\hline \multirow{15}{*}{ 1. Model } & \multirow{3}{*}{50} & $n_{1}$ & 0.1116 & 0.1196 & 0.1042 & 0.1072 \\
\hline & & $n_{2}$ & 0.2140 & 0.2222 & 0.2004 & 0.2006 \\
\hline & & $n_{3}$ & 0.3308 & 0.3586 & 0.3164 & 0.3152 \\
\hline & \multirow{3}{*}{100} & $n_{1}$ & 0.1446 & 0.1512 & 0.1334 & 0.1410 \\
\hline & & $n_{2}$ & 0.2938 & 0.3156 & 0.2790 & 0.2850 \\
\hline & & $n_{3}$ & 0.4756 & 0.5058 & 0.4584 & 0.4628 \\
\hline & \multirow{3}{*}{200} & $n_{1}$ & 0.1988 & 0.2106 & 0.1858 & 0.1966 \\
\hline & & $n_{2}$ & 0.4594 & 0.4860 & 0.4376 & 0.4520 \\
\hline & & $n_{3}$ & 0.7026 & 0.7388 & 0.6866 & 0.6958 \\
\hline & \multirow{3}{*}{300} & $n_{1}$ & 0.2252 & 0.2400 & 0.2114 & 0.2266 \\
\hline & & $n_{2}$ & 0.5262 & 0.5556 & 0.5080 & 0.5224 \\
\hline & & $n_{3}$ & 0.7974 & 0.8250 & 0.7800 & 0.7896 \\
\hline & \multirow{3}{*}{500} & $n_{1}$ & 0.3104 & 0.3312 & 0.2924 & 0.3128 \\
\hline & & $n_{2}$ & 0.7326 & 0.7650 & 0.7112 & 0.7294 \\
\hline & & $n_{3}$ & 0.9524 & 0.9660 & 0.9460 & 0.9506 \\
\hline \multirow{15}{*}{ 2. Model } & \multirow{3}{*}{50} & $n_{1}$ & 0.1172 & 0.1130 & 0.1066 & 0.1118 \\
\hline & & $n_{2}$ & 0.2134 & 0.2100 & 0.1976 & 0.2022 \\
\hline & & $n_{3}$ & 0.3272 & 0.3306 & 0.3056 & 0.3096 \\
\hline & \multirow{3}{*}{100} & $n_{1}$ & 0.1432 & 0.1438 & 0.1286 & 0.1400 \\
\hline & & $n_{2}$ & 0.3088 & 0.3070 & 0.2844 & 0.2976 \\
\hline & & $n_{3}$ & 0.4890 & 0.4888 & 0.4628 & 0.4756 \\
\hline & \multirow{3}{*}{200} & $n_{1}$ & 0.1998 & 0.1966 & 0.1826 & 0.1996 \\
\hline & & $n_{2}$ & 0.4460 & 0.4364 & 0.4208 & 0.4386 \\
\hline & & $n_{3}$ & 0.6938 & 0.6944 & 0.6752 & 0.6870 \\
\hline & \multirow{3}{*}{300} & $n_{1}$ & 0.2308 & 0.2270 & 0.2116 & 0.2326 \\
\hline & & $n_{2}$ & 0.5286 & 0.5164 & 0.5074 & 0.5244 \\
\hline & & $n_{3}$ & 0.7954 & 0.7876 & 0.7768 & 0.7890 \\
\hline & \multirow{3}{*}{500} & $n_{1}$ & 0.3076 & 0.2994 & 0.2802 & 0.3114 \\
\hline & & $n_{2}$ & 0.7304 & 0.7222 & 0.7118 & 0.7288 \\
\hline & & $n_{3}$ & 0.9506 & 0.9470 & 0.9458 & 0.9504 \\
\hline \multirow{15}{*}{ 3. Model } & \multirow{3}{*}{50} & $n_{1}$ & 0.2400 & 0.2020 & 0.2332 & 0.2284 \\
\hline & & $n_{2}$ & 0.4406 & 0.3634 & 0.4334 & 0.4194 \\
\hline & & $n_{3}$ & 0.6502 & 0.5552 & 0.6438 & 0.6274 \\
\hline & \multirow{3}{*}{100} & $n_{1}$ & 0.2878 & 0.2484 & 0.2836 & 0.2828 \\
\hline & & $n_{2}$ & 0.5316 & 0.4458 & 0.5250 & 0.5154 \\
\hline & & $n_{3}$ & 0.7286 & 0.6336 & 0.7210 & 0.7104 \\
\hline & \multirow{3}{*}{200} & $n_{1}$ & 0.3462 & 0.2926 & 0.3402 & 0.3418 \\
\hline & & $n_{2}$ & 0.6316 & 0.5272 & 0.6266 & 0.6208 \\
\hline & & $n_{3}$ & 0.8356 & 0.7552 & 0.8326 & 0.8280 \\
\hline & \multirow{3}{*}{300} & $n_{1}$ & 0.3470 & 0.2938 & 0.3408 & 0.3422 \\
\hline & & $n_{2}$ & 0.6480 & 0.5528 & 0.6432 & 0.6408 \\
\hline & & $n_{3}$ & 0.8722 & 0.7826 & 0.8682 & 0.8652 \\
\hline & \multirow{3}{*}{500} & $n_{1}$ & 0.4126 & 0.3506 & 0.4084 & 0.4136 \\
\hline & & $n_{2}$ & 0.7444 & 0.6428 & 0.7412 & 0.7392 \\
\hline & & $n_{3}$ & 0.9204 & 0.8540 & 0.9178 & 0.9164 \\
\hline \multicolumn{2}{|c|}{$n_{1}=(10,15,25,30)$} & \multicolumn{3}{|c|}{$n_{2}=(20,30,50,60)$} & $n_{3}=(30$ & $5,90)$ \\
\hline
\end{tabular}

Ayrıca üç farklı varyans-kovaryans modeli için $k=3$ ve $k=4$ durumunda $p=$ $50,100,200,300,500$ değerlerine ve $n_{i}$ gözlem sayılarına göre test istatistiklerine ait güç değerleri sırasıyla Şekil 4 ve Şekil 5 'te yer almaktadır. 


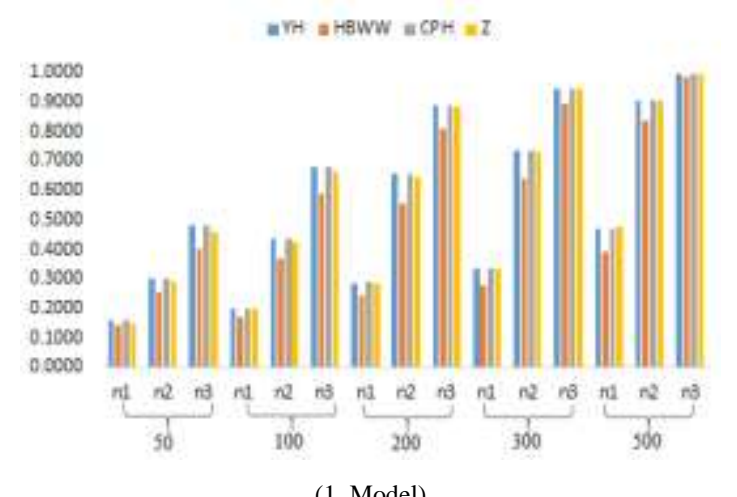

(1. Model)

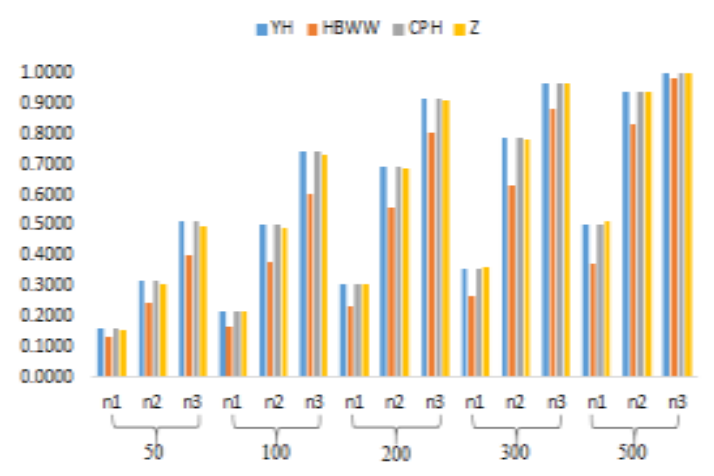

(2. Model)

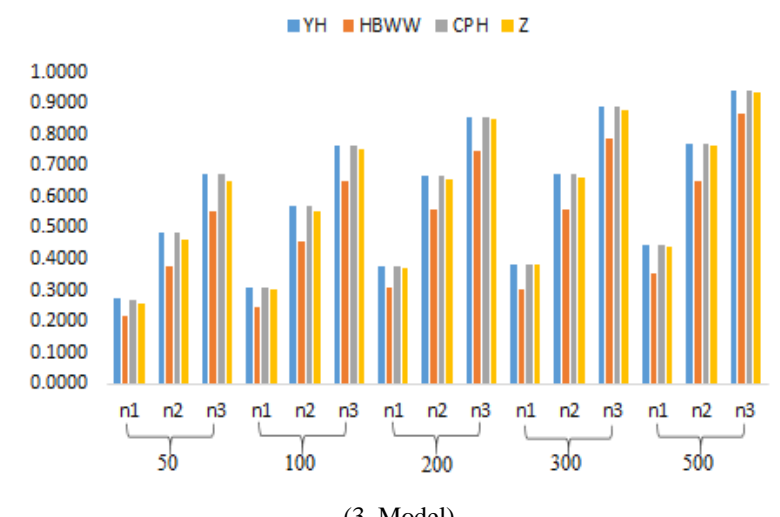

Şekil 4: $\mathrm{k}=3$ durumunda üç farklı varyans-kovaryans modeline göre test istatistiklerinin güç değerleri
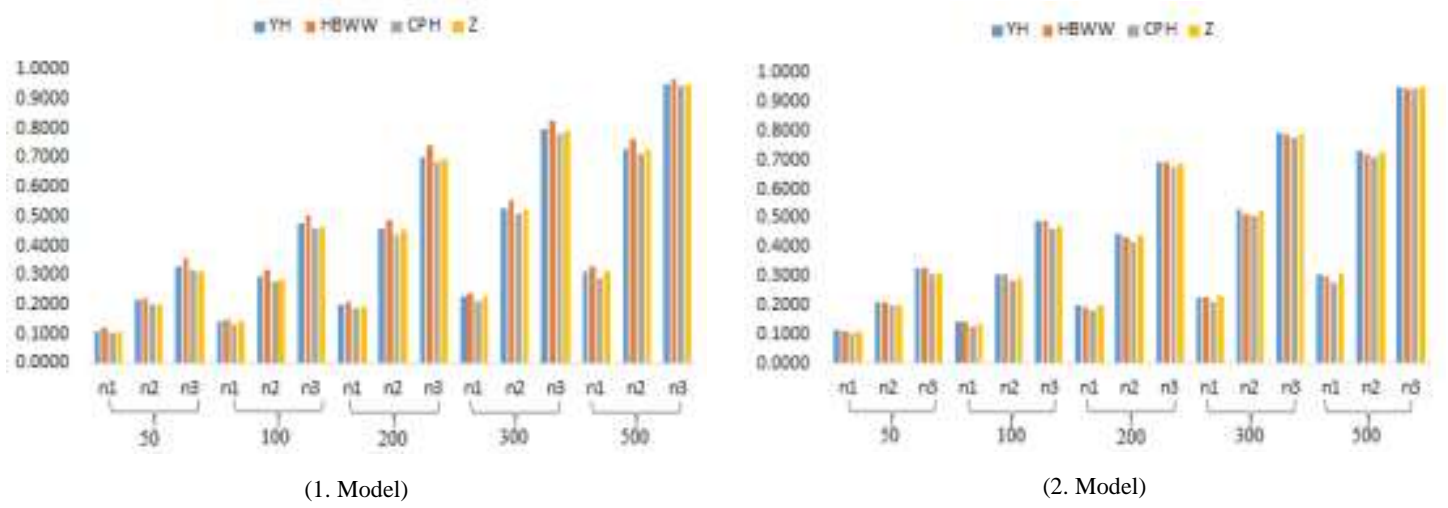

$\varpi \mathrm{YH} \backsim \mathrm{HBWW}=\mathrm{CPH} \backsim \mathrm{Z}$

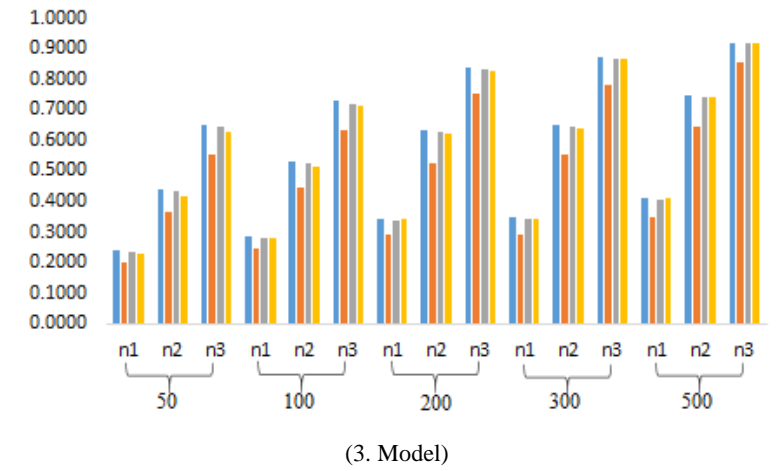

Şekil 5: $\mathrm{k}=4$ durumunda üç farklı varyans-kovaryans modeline göre test istatistiklerinin güç değerleri 
Üç farklı varyans-kovaryans modeli için $\mathrm{k}=3$ ve $\mathrm{k}=4$ durumunda elde edilen güç istatistikleri incelendiğinde bağımlı değişken sayısının küçük olduğu durumlarda test istatistiklerinin performansı daha düşük iken, boyut sayısı arttıkça test istatistiklerinin performanslarının da yükseldiği gözlemlenmiştir. Her iki tabloya göre en küçük güç değerleri $T_{H B W W}^{*}$ test istatistiğinden elde edilmiştir. $T_{Z}^{*}, T_{C P H}^{*}$ ve $T_{Y H}^{*}$ test istatistiklerinin güç değerleri ise daha yüksek bulunmuştur. $T_{Z}^{*}$ test istatistiğinin performansı $T_{C P H}^{*}$ ve $T_{Y H}^{*}$ 'a göre daha iyi olmasına rağmen güç değerleri daha küçük elde edilmiştir. $\mathrm{Bu}$ durum, $T_{Z}^{*}$ test istatistiği için elde edilen I. tip hata yapma olasılıklarının $T_{C P H}^{*}$ ve $T_{Y H}^{*}$ test istatistiklerine göre çok daha küçük olmasından kaynaklanmaktadır.

\section{Gerçek Veri Uygulaması}

$\mathrm{Bu}$ bölümde yüksek boyutlu $k$ örneklem Behrens-Fisher problemlerinin çözümü için önerilen test istatistikleri gerçek bir veri örneği üzerinde uygulanmıştır. Bu amaçla [28] tarafından sunulan ses rehabilitasyon veri seti kullanılmıştır. $\mathrm{Bu}$ veri seti; konuşma sinyallerinden klinik bilgilerin çıkarılması amacıyla 126 konuşma sinyalini karakterize etmek için kullanılan 309 farklı özellik içermektedir. Üstelik [29], yüksek boyutlu kovaryans matrislerinin homojenlik testi için ses rehabilitasyon veri setinden yararlanmıştır.

Çalışmada konuşma sinyallerine ait veriler rassal olarak üç farklı gruba ayrılmıştır. Ayrıca dengeli ve dengesiz gözlem büyüklüklerinde test istatistiklerinin performanslarını karşılaştırmak amacıyla iki farklı gözlem durumu kullanılmıştır. Böylece yüksek boyutlu $k$ örneklem Behrens-Fisher problemleri için önerilen test istatistikleri kullanılarak iki farklı gözlem durumuna göre üç grubun ortalamalar vektörü arasında farklılık olup olmadığı test edilmiştir. $\% 5$ anlamlılık düzeyinde test istatistiklerine ait olasılık değerleri Tablo 6'da yer almaktadır.

Tablo 6. Ses rehabilitasyon veri seti için test istatistiklerine ait olasılık değerleri

\begin{tabular}{ccccc}
\hline$\left(\boldsymbol{n}_{\mathbf{1}}, \boldsymbol{n}_{2}, \boldsymbol{n}_{\mathbf{3}}\right)$ & $\boldsymbol{T}_{\boldsymbol{Y H}}^{*}$ & $\boldsymbol{T}_{\boldsymbol{H B W W}}^{*}$ & $\boldsymbol{T}_{\boldsymbol{C P H}}^{*}$ & $\boldsymbol{T}_{\boldsymbol{Z}}^{*}$ \\
\hline$(20,30,40)$ & .1957 & .2295 & .1996 & .1498 \\
\hline$(30,30,30)$ & .4437 & .4453 & .4453 & .3096 \\
\hline
\end{tabular}

Tablo 6 incelendiğinde dengeli ve dengesiz gözlem büyüklüklerine göre elde edilen olasılık değerleri $\alpha=.05$ 'ten daha büyük olduğu için yokluk hipotezi kabul edilmektedir. $\mathrm{Bu}$ durumda $\% 5$ anlamlılık düzeyinde üç grubun ortalamalar vektörü arasında anlamlı bir farklılık olmadığı söylenebilmektedir.

\section{Sonuç ve Yorum}

Son yıllarda bilgisayar teknolojisinde meydana gelen gelişmeler, büyük boyutlarda verilerin elde edilmesini ve bu verilerin kaydedilmesini kolaylaştırmaktadır. Bu durum değişken sayısının çok büyük olduğu veriler için istatistiksel analizlerin gerçekleştirilmesine imkân sağlamaktadır. Ancak günümüzde kullanılan istatistiksel yöntemler genellikle gözlem sayısının değişken sayısından daha fazla olduğu durumlar ile ilgilenmektedir. Bu nedenle klasik yöntemlerin birçoğu yüksek boyutlu verilerin analiz edilmesinde kullanılamamaktadır. Dolayısıyla yüksek boyutlu veri kavramının giderek yaygınlaştığı ve gelecekte daha da önemli hale geleceği düşünüldüğünde yüksek boyutlu veriler için uygun çözümleme yaklaşımlarının geliştirilmesi ve bu yöntemlerin kullanılması oldukça önemlidir.

$\mathrm{Bu}$ çalışmanın amacı, yüksek boyutlu Behrens-Fisher problemlerinde ortalama vektörlerin eşitliğini sınamak için uygun test istatistiklerini araştırmaktır. $\mathrm{Bu}$ amaçla varyans-kovaryans matrislerinin homojen olmadığı durumlar için literatürde önerilen dört test istatistiği bir simülasyon çalışması ile karşılaştırılmıştır. Test istatistiklerinin 
performansını etkileyen faktörleri gözlemlemek için üç farklı varyans-kovaryans modeli dikkate alınmıştır. Ayrıca her bir test istatistiğinin farklı deneysel koşullar altındaki performansları belirlenmiştir.

Yüksek boyutlu verilerde MANOVA problemlerinin çözümü için yeni bir test istatistiği öneren [21], önerilen bu test istatistiğinin $T_{Y H}^{*}$ 'dan daha iyi bir performans ortaya koyduğunu belirtmektedir. Bizim simülasyon sonuçlarımız da $T_{Z}^{*}$ test istatistiğinin performansının $T_{Y H}^{*}$ 'dan daha iyi olduğunu göstermektedir. Ayrıca varyans-kovaryans matrislerinin heterojen olduğu durumda [21]'in test istatistiğinin [22]'nin test istatistiğinden de daha iyi bir performans ortaya koyduğu görülmüştür.

[23] ise önerdiği test istatistiğini [20] ile [22]'nin test istatistikleri ile karşılaştırmış ve özellikle dengesiz gözlem büyüklüğünde $T_{C P H}^{*}$ test istatistiğinin daha iyi bir performans ortaya koyduğunu göstermiştir. Çalışmamızda incelenen deneysel koşullara göre $k=3$ durumunda $T_{C P H}^{*}$ ve $T_{Y H}^{*}$ test istatistikleri için yakın sonuçlar elde edilirken, grup sayısı arttıkça $T_{C P H}^{*}$ test istatistiğinin performansının daha iyi olduğu görülmüştür. $T_{H u}$ test istatistiği ise birinci varyans-kovaryans modeline göre $T_{C P H}^{*}$ ve $T_{Y H}^{*}$ test istatistiklerinden daha iyi performans göstermektedir. Ancak diğer modellerde $T_{H B W W}^{*}$ test istatistiğinin deneysel hata yapma oranlarının en yüksek olduğu gözlemlenmiştir. Bu durum $T_{H B W W}^{*}$ test istatistiğinin varyans-kovaryans modelinden fazlasıyla etkilendiğini göstermektedir. [23]'te, test istatistiklerinin performansının varyans-kovaryans modelinden etkilendiğini ifade etmektedir.

Bütün sonuçlar dikkate alındığında genel olarak $T_{Z}^{*}$ ve $T_{C P H}^{*}$ test istatistiklerinin daha iyi performans ortaya koyduğu gözlemlenirken, $T_{Y H}^{*}$ ve $T_{H B W W}^{*}$ test istatistiklerinin performansının ise daha düşük kaldığ 1 görülmüşsür. Grup sayısı arttıkça $T_{Z}^{*}$ ve $T_{C P H}^{*}$ test istatistiklerinin performansları yaklaşmaktadır. Ayrıca grup sayısı veya bağımlı değişken sayısı arttıkça, bütün test istatistiklerinin deneysel hata yapma olasılıklarının nominal anlamlılık düzeyine yaklaştığı görülmüştür. Bu durum, bağımlı değişken sayısı ile gözlem sayısı arasındaki oran yükseldikçe önerilen test istatistiklerinin daha iyi sonuçlar ortaya koyacağını göstermektedir.

$\mathrm{Bu}$ çalışma ile yüksek boyutlu ve varyans-kovaryans matrislerinin homojen olmadığ problemlerde, ikiden fazla grup ortalamasını karşılaştırmak için uygun yaklaşımların belirlenmesi hedeflenmiştir. Ayrıca önerilen test istatistiklerinin bir arada değerlendirilmesi ve farklı kovaryans matrisleri altında performanslarının karşılaştırılması bakımından literatüre katkı sağlamaktadır. Böylece varsayımların sağlanmadığı durumlarda uygun istatistiksel çözümleme yaklaşımına karar verilebilmektedir. Ancak test istatistiklerinin performanslar1; varyans-kovaryans matrislerinin yapısından, bağımlı değişken sayısından ve grup sayısından çok fazla etkilenmektedir. Bu durum test istatistiklerini performanslarının farklı deneysel koşullar altında değişmesine neden olmaktadır. Bu nedenle veri setinin özellikleri dikkate alınarak test istatistiklerinin güçleri belirlenmeli ve analizler için en yüksek performansa sahip test istatistiği seçilmelidir. Böylece elde edilen sonuçların doğru ve güvenilir olması beklenmektedir.

\section{Araştırmacıların Katkı Oranı Beyanı}

Mehmet Sandal: Metodoloji, Yazılım, Araştırma, İnceleme ve Düzenleme

Zeki Yıldız: Metodoloji, Araştırma, İnceleme ve Düzenleme, Denetim/Gözlem/Tavsiye

\section{Destek ve Teşekkür Beyanı}

Bu çalışmanın yazarları olarak herhangi bir destek ve teşekkür beyanımız bulunmadığını bildiririz. 


\section{Çatışma Beyanı}

Bu çalışmanın yazarları olarak herhangi bir çatışma beyanımız bulunmadığını bildiririz.

\section{Etik Kurul Onayı ve/veya Aydınlatılmış Onam Bilgileri}

$\mathrm{Bu}$ çalışmanın yazarları olarak herhangi bir etik kurul onayı ve/veya aydınlatılmış onam bilgileri beyanımız bulunmadığını bildiririz.

\section{Kaynakça}

[1] R. Alpar, Uygulamalı Çok Değişkenli İstatistiksel Yöntemler, Detay Yayıncılık, Ankara, 2011.

[2] H. Finch, and B. French, "A monte carlo comparison of robust MANOVA test statistics," J. Mod. Appl. Stat. Methods, 12 (2), 35-81, 2013.

[3] S.S. Wilks, "Certain generalizations in the analysis of variance," Biometrika, 24 (3-4), 471-494, 1932.

[4] H. Hotelling, "A generalized T test and measure of multivariate dispersion," Proceedings of the Second Berkeley Symposium on Mathematical Statistics and Probability, 23-41, 1951.

[5] K.C.S. Pillai, "Some new test criteria in multivariate analysis," Ann. Math. Stat., 26 (1), 117-121, 1955.

[6] S.N. Roy, Some Aspects of Multivariate Analysis, Wiley, New York, 1957.

[7] K. Jiamwattanapong, and S. Chongcharoen, "A new test for the mean vector in high-dimensional data," Songklanakarin Journal of Science and Technology, 37 (4), 477-484, 2015.

[8] Y. Shen, Z. Lin, and J. Zhu, "Shrinkage-based regularization tests for high-dimensional data with application to gene set analysis," Comput. Stat. Data Anal., 55 (7), 2221-2233, 2011.

[9] A.P. Dempster, "A high dimensional two sample significance test," Ann. Math. Stat., 29 (4), 995 1010, 1958,

[10] A.P. Dempster, "A significant test for the separation of two highly multivariate small samples," Biometrics, 16 (1), 41-50, 1960.

[11] Z. Bai, and H. Saranadasa, "Effect of high dimension: By an example of a two sample problem," Statistica Sinica, 6 (2), 311-329, 1996.

[12] S. Chen, and Y. Qin, "A two-sample test for high-dimensional data with applications to gene-set testing," Ann. Stat., 38 (2), 808-835, 2010.

[13] Y. Fujikoshi, T. Himeno, and H. Wakaki, "Asymptotic results of a high dimensional MANOVA test and power comparisons when the dimension is large compared to the sample size," Journal of Japan Statistical Society, 34, 19-26, 2004.

[14] M.S. Srivastava, and Y. Fujikoshi, "Multivariate analysis of variance with fewer observations than the dimension," J. Multivar. Anal., 97 (9), 1927-1940, 2006.

[15] M.S. Srivastava, "Multivariate theory for analyzing high-dimensional data," Journal of the Japan Statistical Society, 37 (1), 53-86, 2007.

[16] J.R. Schott, "Some high-dimensional tests for a one-way MANOVA," J. Multivar. Anal., 98 (9), 1825-1839, 2007.

[17] J.T. Zhang, and J. Xu, "On the k-sample Behrens-Fisher problem for high-dimensional data," Science in China Series A:Mathematics, 52 (6), 1285-1304, 2009.

[18] T. Yamada, and M.S. Srivastava, "A test for the multivariate analysis of variance in high-dimension," Commun. Stat. Theory Methods, 41, 2602-2612, 2012.

[19] M.S. Srivastava, and T. Kubokawa, "Tests for multivariate analysis of variance in high dimension under non-normality,” J. Multivar. Anal., 115, 204-216, 2013.

[20] T. Yamada, and T. Himeno, "Testing homogeneity of mean vectors under heteroscedasticity in highdimension," J. Multivar. Anal., 139, 7-27, 2015.

[21] B. Zhou, "Linear hypothesis testing for high-dimensional data under heteroscedasticity," Phd Dissertation, National University of Singapore, Singapore, 2016.

[22] J. Hu, Z. Bai, C. Wang, and W. Wang, "On testing the equality of high dimensional mean vectors with unequal covariance matrices," Ann. Inst. Stat. Math., 69 (2), 365-387, 2017. 
[23] M. X. Cao, J. Park, and D. J. He, "A test for the k sample Behrens-Fisher problem in high dimensional data,” J. Stat. Plan. Inference, 201, 86-102, 2019.

[24] M. Aoshima, and K. Yata, "Two-stage procedures for high-dimensional data," Seq. Anal.s, 30 (4), 356-399, 2011.

[25] H. Yanagira, and K.H. Yuan, "Three approximate solutions to the multivariate Behrens-Fisher problem," Commun. Stat. Simulation Comput., 34 (4), 975-988, 2005.

[26] T. Kawasaki, and T. Seo, "A Two Sample Test for Mean Vectors with Unequal Covariance Matrices," Commun. Stat. Simulation Comput., 44 (7), 1850-1866, 2015.

[27] P. Sukcharoen, and S. Chongcharoen, "A test on the multivariate Behrens-Fisher Problem in highdimensional data by block covariance estimation," J. Math. Stat., 15 (1), 44-54, 2019.

[28] A. Tsanas, M.A. Little, C. Fox, and L.O. Ramig, "Objective automatic assessment of rehabilitative speech treatment in Parkinson's disease,” IEEE Trans. Neural Syst. Rehabilitation Eng., 22 (1), 181$190,2014$.

[29] A. Qayed, and D. Han, "Homogeneity test of several high-dimensional covariance matrices for stationary processes under non-normality," arXiv preprint arXiv:2008.09259, 2020. 